\title{
VITAMIN D3 DEFICIENCY IN PATIENTS \\ WITH ANKYLOSING SPONDYLITIS AND RELATIONSHIP WITH THE DISEASE ACTIVITY
}

\section{Olena Grishyna ${ }^{1}$ \\ Olena Menkus ${ }^{2}$}

DOI: https://doi.org/10.30525/978-9934-26-050-6-14

Vitamin D modulates the immune responses in certain diseases of autoimmune diseases, such as multiple sclerosis, diabetes mellitus, psoriasis, systemic lupus erythematosus, rheumatoid arthritis. Its biological effects are mediated by the vitamin D receptor (VDR), which belongs to the family of nuclear hormone receptors and is expressed in cell types, including macrophages, dendritic cells, B- and T-lymphocytes, and neutrophils [1; 2, p. 184-191]. A variety of studies have shown vitamin D3 deficiency in patients with ankylosing spondylitis (AS), but the role of this deficiency in the pathogenesis of the disease remains unclear [3; 4, p. 54].

Objective was to assess serum vitamin D3 level of in patients with AS and explore possible relationship with the disease manifestations.

\footnotetext{
${ }^{1}$ SI «Mechnikov Institute of Microbiology and Immunology of National Academy of Medical Science of Ukraine», Ukraine ${ }^{2} \mathrm{SI}$ «Mechnikov Institute of Microbiology and Immunology of National Academy of Medical Science of Ukraine», Ukraine
} 
Methods. Twenty four patients with AS were evaluated, 6 female and 18 male. The patients were diagnosed with ankylosing spondylitis according to the modified New York criteria [5, p. 361]. The inclusion criteria were the absence of total spinal ankylosis, the Bath Ankylosing Spondylitis Disease Activi ty Index (BASDAI) $\geq 4$ [6, p. 2286], total back pain score $\geq 4$ based on a 0-10 numeric rating scale (NRS; 0 represents «no pain», 10 represents «worst pain possible»). Exclusion criteria: patients with rheumatoid arthritis, gout, cognitive impairment, mental illness, surgical history, chronic heart failure, serious infection within the previous four weeks, taking vitamin D supplements in previous three months, those who were pregnant. Skin type was classified by T.B. Fitzpatrick [7, p. 869]. C-reactive protein (CRP) and erythrocyte sedimentation rate (ESR) were also used to objectify disease activity.Thirty healthy subjects served as a control group.

Results. This cross-sectional study was conducted in June-October 2020. Twenty four patients with AS were evaluated, 6 female and 18 male. The average serum $25(\mathrm{OH}) \mathrm{D}$ level $(\mathrm{M} \pm \mathrm{SD})$ was significantly lower in patients with AS comparing to control group $(31.2 \pm 8.5) \mathrm{nmol} / \mathrm{L}$ vs $(43,4 \pm 11,3)$ $\mathrm{nmol} / \mathrm{L}, \mathrm{p}<0,05$. The patients were divided into 2 groups depending on D3 level. Group 1 consisted of 11 (45.8\%) patients, with vitamin D3 deficiency and 13 patients $(54,2 \%)$ with vitamin D3 level $>30 \mathrm{nmol} / \mathrm{L}$ formed group 2, respectively. The patients did not differ $(\mathrm{M} \pm \mathrm{SD})$ in age $(38.4+11.2)$ vs $(37.8+9.4)$ years and the duration of the course of the disease from the moment the first symptoms appeared $-(12.3+4.1)$ vs $(11.9+3.5)$ years, respectively. Among all patients skin type 2 and 3 by T.B. Fitzpatrick were found only, no difference between all groups, $p>0,05$. The characteristics of the disease activity are presented in the table.

Table

The characteristics of the disease activity in patients with AS.

\begin{tabular}{|l|c|c|c|}
\hline $\begin{array}{c}\text { Characteristics } \\
\mathbf{( M} \pm \mathbf{S D})\end{array}$ & Group 1 (n=11) & Group 2 (n=13) & p \\
\hline BASDAI & $7.1 \pm 1.8$ & $6.2 \pm 1.5$ & 0.097 \\
\hline Back pain & $6.8 \pm 1.7$ & $5.6 \pm 1.6$ & 0.040 \\
\hline C-RP $(\mathrm{mg} / \mathrm{L})$ & $24.4 \pm 7.3$ & $19.8 \pm 5.7$ & 0.048 \\
\hline ESR & $31.7 \pm 9.8$ & $27.7 \pm 8.1$ & 0.142 \\
\hline
\end{tabular}

Despite the small sample size, we see a higher disease activity in patients with vitamin D3 deficiency. Significant differences were obtained between the levels of total back pain and CRP.

Conclusion. Vitamin D3 deficiency was frequently found in AS patients. Prospective studies are needed to assess its role in the development of the 
disease. You should also study the effect of correcting the level of vitamin D3 on the course of the pathological process.

Disclosure statement. The authors report no conflicts of interest.

\section{References:}

1. Vaidya B., Nakarmi S. (2019) Vitamin D in Rheumatic Diseases: Interpretation and Significance. Fads and Facts about Vitamin D. Publishes: IntechOpen. Retrieved from: https://www.researchgate.net/publication/33512

2. Gatenby P, Lucas R., Swaminathan A. (2013) Swaminathan A. Vitamin D deficiency and risk for rheumatic diseases: an update. Current Opinion in Rheumatology (electronic journal), vol. 25, pp. 184-191. Retrieved from: https://www.researchgate.net/publication/235391168

3. Essouma M., Noubiap N. (2017) Are Systematic Screening for Vitamin D Deficiency and Vitamin D Supplementation Currently Feasible for Ankylosing Spondylitis Patients? International Journal of Inflammation (electronic journal). Retrieved from: https://www.hindawi.com/journals/iji//

4. Deng S., Yi He, Nian X., Sun E., Li Li, 2019. Relationship between Vitamin D levels and pain and disease activity in patients with newly diagnosed axial spondyloarthritis. Int J Nurs Sc (electronic journal), vol. 7(1), pp. 54-59. Retrieved from: https://pubmed.ncbi.nlm.nih.gov/32099860/

5. Van der Linden S, Valkenburg HA, Cats A. (1984) Evaluation of diagnostic criteria for ankylosing spondylitis. A proposal for modification of the New York criteria. Arthritis Rheum, vol. 27(4), pp. 361-8.

6. Garret S.L., Jenkinson T.R., Whitelock H.C. et al (1994) A new approach to defining disease status in ankylosing spondylitis: Bath Ankylosing Spondylitis Disease Activity Index (BASDAI). J. Rheumatol, vol. 21, pp. 2286-91.

7. Fitzpatrick T.(1988) The validity and practicality of sun-reactive skin types I through VI. Arch Dermatol., vol. 124, pp. 869-871. 